\title{
A Trauma-Informed Transition Model for New Entrants with Dysregulated Behaviours
}

\section{A. Hunter-Dehn ${ }^{1}$ (D)}

Received: 13 May 2021 / Accepted: 27 July 2021 / Published online: 16 September 2021

(C) The Author(s) 2021

\begin{abstract}
The Riroriro programme was a response to the needs of children with extremely dysregulated classroom behaviours, resulting from sustained exposure to traumatic high-stress and high-deprivation environments from pre-birth to school age. Evaluation of the accounts of key individuals involved in the pilot found that participants had improved emotional regulation abilities and interpersonal skills during and up to 1 year after the intervention. Academic performance was not improved significantly, but the interviewees' accounts suggested that "academic readiness" had been achieved. In line with previous studies, the results indicate preliminary support for the effectiveness of the Riroriro programme in supporting children who have experienced trauma to become mainstream classroom ready. These results suggest that a whole-school, multi-tiered approach providing support at the student, school personnel and system levels can help mitigate the effects of trauma.
\end{abstract}

Keywords Dysregulated behaviours · Education · Emotional regulation · Trauma . Classroom

\section{Introduction}

\section{Trauma in Early Development}

As a single event or repeated pattern, trauma refers to situations which directly threaten one's life or those of others and/or overwhelms one's resources to cope (Herman, 2015). Trauma and its impact on children is of particular concern in New Zealand after research commissioned by the Ministry of Social Development showed that one half of children in the large scale study had experienced at least one adverse childhood experience by 4.5 years of age (Walsh et al., 2019). Māori (Tangata Whenua-people of the land) experience trauma in distinct ways, often as a

\footnotetext{
A. Hunter-Dehn

amandahunterdehn@gmail.com

1 Presbyterian Support Northern, Auckland, New Zealand
} 
result of colonisation, systemic inequalities and experiences of racism and discrimination. Māori are disproportionately represented in violence, poverty and crime statistics, all of which are linked with experiences of childhood trauma (Pihama et al., 2017).

Exposure to traumatic events in early life has been found to cause changes in structures in the brain and alterations in chemical activity (Tobin, 2016). The physical impacts of trauma on the brain express in a number of ways which have been summarised throughout this article under three categories: emotional regulation, social skills and academic achievement.

Emotional Regulation Children who have experienced trauma often have trouble regulating their emotions in appropriate ways because they have learnt to remain in a near-constant state of emergency. Natural stress responses can include a rapid heart rate, increased blood pressure and a focus on seeking safety resulting in exaggerated reactivity, poor decision making, and maladaptive emotional and behavioural responses to stressful situations (Perry et al., 1995). Practically speaking, traumatised children respond to situations that they find stressful by acting out with aggression, defiance, hypervigilance and mood swings (Cole et al., 2005) or with dissociative behaviours such as daydreaming, disengagement, withdrawal, or passivity (Oehlberg, 2008). An inability to recognise and understand their own emotions means that traumatised children can have difficulties understanding or modifying their own behaviours (Putnam, 2006).

Social Skills Children who have experienced trauma may distrust school staff because past experiences with authority figures have taught them that they will not keep them safe. As a result they may view teachers' rules and disciplinary actions as punishment which can lead to re-traumatisation and increase the likelihood that these children will be repeatedly subject to school discipline and exclusion (StreeckFischer \& van der Kolk, 2000). This can make the school environment feel like an unfriendly place and mean that children become distrustful of adults and fellow students making it difficult to form secure attachments with school staff and peers (Hepp et al., 2021).

Academic Achievement The impacts of childhood trauma can make it challenging for children to achieve positive educational outcomes. Traumatised children can develop sensory processing difficulties as a result of poor information processing abilities and attention spans which can make learning to read and write difficult (Streeck-Fischer \& van der Kolk, 2000). Studies have shown that by early childhood, maltreated children demonstrate less flexibility and creative problem solving abilities compared to other children. There is a demonstrated connection between traumatic experiences and decreased IQ and reading ability (Delaney-Black et al., 2002), increased absence from school (Hurt et al., 2001), and in some cases dropping out from the education system altogether (Porche et al., 2011).

\section{Trauma in Schools and Trauma Informed Care}

Because traumatised children have difficulties with emotional regulation and social interactions, they are likely to be perceived as defiant and face punitive 
disciplinarian consequences in a mainstream educational environment. Addressing challenging behaviours using traditional, disciplinary approaches such as detentions and suspensions, have not been found to be an effective way to support children who have experienced trauma (APA, 2008; Overstreet \& Chafouleas, 2016). A number of schools are now exploring alternative approaches to supporting these children and taking steps to become 'trauma-informed' (Craig, 2015).

Trauma-informed care (1) realises that trauma has a widespread impact on individuals and those around them and has an understanding of paths to recovery, (2) recognises the signs and symptoms of trauma, (3) integrates trauma knowledge into policies, programmes, and practices and (4) Seeks to avoid re-traumatisation (Bath, 2008). Within a trauma informed school, staff at all levels receive professional development in and have a basic understanding of trauma and how it impacts learning and behaviour (Cole et al., 2005).

While the research on trauma-informed approaches is still growing, a number of trauma-informed models have been implemented in education environments around the world with demonstrated success. Herrenkohl et al. (2019) found that classroombased and school-wide interventions allow for trauma-informed solutions to be fully integrated into the fabric of day-to-day school operation and are therefore well positioned to be sustainable. School-wide interventions have been linked to improved engagement, improved attendance, fewer disciplinary referrals (Dorado et al., 2016), improved relationships, academic competence, emotional well-being (Rodenbush, 2015), decreased suspensions and reductions in Post-Traumatic Stress Disorder (PTSD) symptoms (Day et al., 2015). School-based interventions also increase teacher confidence and competence in working with children who have experienced trauma, improving the overall quality of the learning environment (Shamblin et al., 2016).

\section{Riroriro: A Transition Model}

The Riroriro pilot was a school-wide intervention that brought together tailored classroom lessons, teacher training, therapy and wraparound support to build each child's readiness to transition into the mainstream classroom. The pilot focussed on six children, who were placed in the Riroriro classroom for almost one school year. The target children were 5 to 7 years of age and came from a range of ethnic backgrounds-half of the participants identified as NZ Māori. This group is referenced throughout this study as the "target children" and individually as "target child".

Each of the six children had experienced trauma at some stage in their lives, including but not limited to either witnessing or having experienced physical and/or emotional abuse, neglect and suspected drug exposure in utero. Beyond the realms of the pilot and the school, the lived reality for many of these children remained complex and unstable during and following the pilot. The six target children exhibited dysregulated behaviours, had poor emotional regulation abilities and lacked basic social skills. Additionally, the target children were not performing at the expected academic level for their age group. 
The school constructed a purpose-built classroom for Riroriro designed to provide intensive learnings in emotional regulation and social skills and equip the target children with the skills needed to participate in mainstream classrooms. Riroriro was staffed by an experienced teacher who acted as the primary attachment figure for the target children and worked closely with parents and caregivers to keep them up to date with their child's progress and provide them with tools and techniques that they could use in the home environment. The classroom also included a teacher aide whose role included assisting with classroom activities and transitions from Riroriro back into mainstream classrooms.

The Riroriro teacher initially focussed on creating a safe and supportive environment in the specialist classroom in which relationships could be built with the target students (Capo et al., 2017). Routines were introduced to bring a sense of structure and consistency (Bilmes \& Heroman, 2005). Following this the teacher moved onto activities and lessons that facilitated emotional regulation and social skills as well as academic lessons:

- Emotional Regulation Songs, stories, and play activities were used to facilitate skill building and emotional regulation strategies (Scarpa \& Reyes, 2011). Because trauma-impacted children struggle to read emotions and differentiate between emotional states (Craig, 2015) the target children needed to be taught to recognise their own emotions and arousal states and were given self-regulation strategies to use when they were in an aroused state (Franzen, 2019). Selfregulation strategies included mindfulness and breathing exercises (Boyd et al., 2018) and moving to a safe space when target students became dysregulated (Cole et al., 2005).

- Social Skills Lessons included key social skill building such as conflict resolution, problem-solving skills, social communication and encouraging behaviours such as empathy, accountability and friendship (NCTSS, 2017). The teacher used techniques such as mirroring, describing behaviours and setting clear expectations and boundaries to clearly delineate between acceptable and unacceptable social behaviours (NCTSC, 2008).

- Academic The programme was initially designed to work on academic skills alongside emotional regulation and social skills. This was reassessed in the first term of the pilot and it was decided that academic work would need to be held off until the children could become "curriculum ready".

While the target children were in the Riroriro classroom the rest of the school were becoming trauma informed to prepare for target students transitions. All junior school teaching staff and senior management staff were sent to professional development training, and encouraged to read literature on and expand their knowledge of trauma-informed practices (NCTSC, 2008). Ensuring that all junior school staff were trauma-informed meant that any teacher would be able to work with the target children, ensuring the sustainability of the programme as the target children transitioned through mainstream classrooms each year.

To avoid re-traumatisation of the target children and ensure subject matter expertise on trauma was always available to school staff, a full-time therapist was engaged 
on-site for the duration of the pilot. Research has demonstrated that therapeutic intervention for children who have experienced trauma is beneficial when the practitioner is physically present in the school daily, integrated within school routines, and has ongoing relationships with students, teachers, and staff (Howley et al., 2019).

The children attended between one and three one-hour sessions with the therapist each week. The therapist was able to provide an accurate assessment of the child and used a variety of therapeutic approaches, primarily Child Centred Play Therapy (CCPT), a psychotherapeutic approach that has been found to be effective in supporting children who have experienced trauma (Humble et al., 2018). The therapist provided advice and guidance to the Riroriro teacher, other staff members within the school and the target children's caregivers. The school also sought out a Research and Practice Interpreter who provided additional therapeutic supervision, guidance and advice. The Riroriro classroom intervention lasted for approximately 1 year and following this, students were gradually transitioned into their mainstream classrooms.

The purpose of this study was to determine the effectiveness of the Riroriro pilot at developing the target group of children's readiness to transition into mainstream classrooms by capturing key staff members' perceptions of the interventions impact on the target children's (1) emotional regulation skills (2) social/interpersonal skills and (3) academic achievement.

\section{Methods}

\section{Design}

This study used a qualitative design with semi-structured interviews to gain a rich understanding of key informants' perceptions of the pilot and its success in meeting its goals. A series of personal reflections authored by the teacher placed in the Riroriro classroom were used as secondary data sources. Informants included the Riroriro teacher, the principal of the school, mainstream teachers who had Riroriro target children transitioned into their classrooms, and the therapist engaged in the school.

\section{Ethical Considerations}

Participants gave fully informed, written consent prior to participating in the evaluation. Given the sensitive nature of trauma research, particular care was taken to ensure that the identities of the target children who participated in the programme were protected. Parents and caregivers were consulted by the Riroriro teacher prior to the evaluation beginning and were provided with an information sheet and the researchers contact details should they have any questions, concerns or requests. This evaluation has been conducted in line with the Presbyterian Support Northern Research and Evaluation Ethics Policy and the evaluation plan was reviewed internally and externally in line with this policy. 


\section{Data Collection}

This study used a semi-structured interview guide based on the intended outcomes of the pilot. The guide included questions about the key informants' experiences of the children prior to, during, and after the pilot intervention. Each interview lasted 30-60 min. The evaluator conducted the interviews in the winter of 2020 in a private interview room in the school building. Interviews were audio recorded and transcribed word for word using the AI software Otter.

\section{Data Analysis}

This study used a deductive, thematic content analysis based on the guidelines of Braun and Clarke (2006). A deductive approach was selected because it allows for the interpretation of identifiable themes and patterns, in this case: emotional regulation, interpersonal skills and academic achievement. Analysis involved a detailed reading of the data corpus, identification of data sets, identification of initial themes and additional themes and theme categorising.

Further analysis of the coded data segments helped to demonstrate connections and discrepancies between interviewees' opinions. The opinions and views expressed by interviewees were triangulated with diary entries from the Riroriro teacher to test the validity of interviewee information, ensure consistency in recall of events and sentiments and help develop a comprehensive understanding of the intervention and its impacts. A final analysis of the data then related back to the original research question and existing literature to determine the effectiveness of the Riroriro programme.

\section{Findings}

The results of this study fit into four thematic areas (1) Emotional Regulation, (2) Interpersonal Skills, (3) Academic Achievement and (4) Trauma Informed School.

\section{Emotional Regulation}

Informants were able to articulate desirable behaviours such as identifying and communicating feeling, focusing attention and calming down. It was clear that school staff had a strong understanding of emotional regulation and how this should look in practice. Informants were also able to provide relevant examples of witnessing these behaviours in the six target children following the Riroriro intervention. In the following examples, two informants describe instances where they witnessed a target child recognising and verbalising emotions:

He is willing to stand up for himself and tell someone when they're doing stuff that he doesn't like, but it's not just a "NO" anymore. It's "you're making me feel frustrated". [P7]

He will stand in front of me with his head down and shout "I am angry". [P12] 
Informants spoke about witnessing all six of the target children using tools and techniques to calm themselves down when they became overwhelmed or upset. Two of the most common techniques mentioned were using breathing and mindfulness to calm down in an emotionally heightened situation and removing one's self from the situation:

[Child] said he was so excited that he wanted to punch his tower over but didn't want it to break so he would just breathe instead. [P12]

He had learned to remove himself from the classroom, to go walk it off or to go sit in a corner quietly by himself until he had calmed down. I know that you learned that in Riroriro. Those were specific strategies that they worked on. And I watched them do it. [P9]

Informants also spoke about a reduction in emotional outbursts that could often involve "screaming" [P2], "shouting" [P2], "intimidation" [P10] and "violence" [P6, P11]. Informants' accounts of the target children's behaviour post-intervention suggested that the emotional regulation skills learnt in the Riroriro classroom were transferable to the playground as well as the mainstream classrooms for many of the target children. An informant provided an example of a target child demonstrating self-control in the playground:

I always come back to [child] because he was the worst of them all. [...] He didn't give a s**t about anybody. Particularly if he was upset, his brain went offline. Now if he gets into a situation where another child is upsetting him, even hitting him, he will not hit back. I haven't seen him hit back. He's got enough self-control to understand that this other child is out of control and he's not. [P5]

\section{Interpersonal Skills}

Prior to the Riroriro pilot the target children had difficulty with interpersonal skills such as admitting fault, apologising, and displaying empathy [P6]. The informants spoke about improvement in these behaviours in the target children generally and provided specific examples of four of the target children interacting in prosocial ways. The two most common prosocial behaviours that were discussed were admitting fault and apologising and displaying altruistic behaviour such as comforting other children when they were upset:

[The target child] talked about having the ball taken from him and then getting into a fight. He was happy to [talk to the child who he had fought with] and entered into the conversation well. He listened and eventually said sorry, recognising that he was part of the problem. [P12]

There was one nice moment when [child one] hit [child two] on the face with [a foam disk] because he "didn't like him" and all the boys turned away from [child one] and made [child two] feel better. They got him an icepack from the fridge, they rubbed his back, got tissues for his tears and sat with him until he was okay. [P12] 
Informants also discussed how the six target children built strong interpersonal relationships amongst themselves which lasted through their transition into the mainstream environment. Informants spoke about a number of the target children using the interpersonal skills learned in Riroriro to form bonds and relationships with children outside of the programme as well:

I see him out there, running around with other kids. [...] Just before we went into lockdown, [he] said something we never thought he would say: '[Mainstream child] is my friend'. He started making friends and setting boundaries with people and talking to people. He has his core people that he really loves and cares about, but he can play with anyone in the classroom now. I never would have expected that from him before. [P7]

Informants spoke about how the prosocial behaviours displayed by the target children generally, has meant that mainstream children now feel comfortable reciprocating these behaviours, not because they have been coached or told to treat the target children any differently but because they have a genuine interest in spending time with the target children:

Well, [one of the boys] found himself a girlfriend after about one week. That lasted the rest of the year. We were amazed. He was thrilled to be in there with her. [P9]

And to just see [another Riroriro child] be able to make friendships and decide on relationships and make connections is just so wonderful and he loves it. One of the girls brought in a necklace for him that she had made at home and you see it just affected [him]. [P7]

\section{Academic Performance}

All of the informants acknowledged that of the six target children, five were "not where they should be academically" [P10] and likely never would be. However, several of the informants caveated that opinion with explanatory statements that mitigated or rationalised the target children's lower-than-expected academic abilities. For example, when speaking about academic ability some informants pointed out learning difficulties that impacted some of the children's cognitive abilities:

So this is still really affected by his ADHD, he's still currently unmedicated. That really hinders his ability to maintain things in the academic sphere. But when he is focused, he's able to produce work that I never would have expected from him at the start of the year. [P7]

During the Riroriro programme several of the informants used their knowledge and understanding of trauma to make allowances or exceptions for the target children and celebrate small victories that appropriately matched their abilities. These included demonstrating pride in achievements such as using the correct punctuation in a sentence [P12], being able to focus on a reading activity for a sustained period of time [P5], or being able to attend reading recovery: 
Academically we have now got to a stage where [child] can attend Reading Recovery. There is no way that he could have done that before. He just never would have concentrated or built a relationship because the reading recovery teacher is pretty firm. [P10]

Just being able to function in a classroom setting and follow the routines and structures of the day and engage with the programme alongside everybody else has been really amazing [P5].

When asked about academic achievement, teachers were not inclined to point out that a child was behind. Instead informants framed the target children as being in a position to engage with the mainstream curriculum having learnt to manage their emotions and navigate social interactions in a healthy way:

Riroriro was to help them with emotional and social regulation. To build their executive functions [and] to help them manage the trauma that they've had and to be able to cope with everyday school life. It was to sort out everything that you need to engage with the curriculum. [P10]

\section{A Trauma-Informed School}

This evaluation found that much of the success of the Riroriro pilot can be attributed to the whole-of-school approach which recognised the target students would eventually return to their mainstream classrooms. An exclusionary approach that made no plans for the students to re-enter the mainstream environment would be unsustainable as any outcomes would be challenging to maintain. This was recognised by school staff who spoke about this as an integral part of the pilot programme:

The [mainstream teachers] knew that their goal was to have that child back in their room. We hoped it would create a continued and vested interest in that child rather than "phew don't have to deal with that anymore". [P6]

One staff member spoke about the importance of the trauma-informed approach and ensuring that all the teachers in the school—not just the Riroriro teacher-were able to understand the behaviours of the children and respond in a trauma-informed way:

The mainstream class [needs to] be on board with the understanding of brain trauma, it was really important. For it to be a success, those teachers had to be confident that at any particular time if there was a child from that group that went off it would be dealt with and it was. It was really important, both to the integrity of the program, but also to its success. [P5]

Having a solid foundational knowledge of trauma and the ways it affects behaviour was an important success factor for the informants, many of whom spoke about having a better understanding of the children's behaviour and more tools to use because of the professional development that they had undertaken:

It's given the people that are dealing with the boys more of an understanding of why they might be acting out or what's going on as opposed to they're just naughty. [P2] 
I think it's given us a lot of patience. Looking at a child and thinking "why is that happening' before you actually react or respond. [It has helped being able to] build up a bank of strategies to be able to deal with different behaviours. [P11]

Ensuring that the entire school was trauma informed also helped to build relationships between staff members in the school. Informants spoke about feeling supported by the Riroriro teacher and other staff in the school who were all able to support each other through the transition. One teacher spoke about struggling with a target student and receiving moral and practical support from another teacher which enabled him to better support his own student:

Early on, I thought this kid hates me because I'm being firm with him and I'm giving him all those things that he actually needs but might not like. I ended up having a bit of a moment. [The other staff] really supported me through that moment. We talked about strategies, and I had a good vent. [P10]

Aside from direct references to being trauma informed, the trauma-knowledge held by the interviewees was clear in the ways that they described the outcomes of the programme. Informants had an excellent understanding of emotional regulation and prosocial behaviour as well as how behaviours can become disorganised in children who have experienced trauma. They recognised and encouraged self-regulatory behaviours that may have otherwise been discouraged in a conventional mainstream environment. They paid particular attention to prosocial interactions and the children's abilities to make and maintain close friendships. They were able to recognise the children's academic abilities and alter their practice to better meet their needs and were able to celebrate appropriate achievements and victories.

These trauma-informed behaviours and beliefs engendered an environment in which the target children were able to form secure attachments with staff and other students as well as understand and manage their emotions and navigate the school at an appropriate and sustainable pace for their individual needs. This meant that classrooms and playgrounds were calmer following the intervention and staff and children were more relaxed:

You can feel the change in the playground. [It] is just so much calmer than it has ever has been before. And I think it's because the other kids know that there aren't ticking time bombs out there as well. [P2]

\section{Discussion}

The purpose of this study was to determine if the Riroriro pilot was successful in meeting its objectives of (1) improving the target children's emotional regulation abilities, (2) interpersonal skills and (3) academic achievement and if improvements were observed, did they hold post-intervention when the target children were engaged in mainstream classrooms. 
Finding 1 Informants reported that students who were engaged in the Riroriro intervention experienced an improvement in emotional regulation and social skills.

This result aligns with the current literature regarding trauma-informed care in schools. When children who have experienced trauma have a safe space with trusted adults (Capo et al., 2017; SAMHSHA, 2013), learn about their own emotions and are given skills to manage these appropriately (Boyd et al., 2018) and are taught to interact in positive prosocial ways (NCTSS, 2017), they can successfully regulate their emotions and utilise healthy interpersonal skills.

The fact that the improvements in emotional regulation and socials skills were maintained 1 year after the intervention is likely attributable to the whole school approach. This approach allowed for trauma-informed solutions to be integrated into the fabric of day-to-day school operation and was well positioned to be sustainable (Herrenkohl et al., 2019). Mainstream teachers reported thinking about the root of dysregulated behaviours and also viewed emotional regulatory behaviours, such as removing oneself from a classroom or shouting "I'm angry", as positive. Behaviours such as these in an environment that was not trauma informed might have been viewed as defiant and been met with disciplinary actions which can be ineffective in supporting children to meet behavioural expectations (APA, 2008; Streeck-Fischer \& van der Kolk, 2000). Teachers recognised these behaviours as positive selfregulation, reinforcing that the teaching staff all had a solid grounding in traumainformed approaches.

Finding 2 Informants reported that they did not observe an improvement in academic achievement post-intervention.

A possible interpretation of this results is that the programme was overly ambitious in looking to improve the target children's academic achievement during the intervention period. There is a great deal of evidence demonstrating the positive relationship between emotional regulation and academic achievement. Mancini (2020) evaluated an intervention that taught emotional regulation skills to immigrant and refugee youth who had experienced trauma and found strides in academic functioning for most participants. There is also evidence to suggest that improving the interpersonal skills of children can impact academic achievement (Durlak et al., 2010). Additionally, research has shown that positive attachments and interpersonal relationships - such as those nurtured during the Riroriro pilot-play a role in buffering the effects of trauma (Ludy-Dobson, \& Perry, 2010). Given the positive relationship between these factors it is not unreasonable to hypothesise that the target children will see academic gains if the improvements in emotional regulation and interpersonal skills persist post-intervention.

While informants reported no significant differences in participants' academic achievements following the Riroriro intervention, they did point to other achievements that they had witnessed such as being able to focus on work for sustained periods of time or attend reading recovery. While test scores are the generally accepted method for measuring academic achievement, improvements in attention span and ability to engage in academic tasks is an achievement in itself. When taken with the informants' reports that the school is now calmer and that there is a reduction in 'meltdowns' which would have previously interrupted classroom learning it appears 
that the groundwork has been laid for the target children to be poised to begin working on the more traditional aspects of academia.

The results of this study show promise that the Riroriro programme could be replicated by other schools to address social and emotional dysregulation in children who have experienced trauma. A well-researched, trauma-informed approach has been shown to be key. Other elements that have likely contributed to the positive outcomes seen here include the excellent teacher to student ratio in the unit and ongoing therapeutic sessions with a trained, onsite therapist. The programme also relied on the parents and caregivers of the target children being supportive of the goals of the programme and committing to practical elements such as ensuring that the child's basic needs are met and that the child attends school on a regular basis.

In looking to replicate this model, others would be advised to incorporate culturally specific elements to better fit the New Zealand education context. It has been noted by scholars that there is a tendency for trauma-informed approaches to be used in New Zealand with little or no recognition of the need for cultural approaches within such constructs. This is likely because trauma-informed care is a relatively new concept in New Zealand and research and literature in this space tends to be carried out overseas. Future iterations of the programme should look to integrate a framework of culturally specific interventions that utilise Indigenous approaches to understanding and working with collective trauma experiences (Pihama et al., 2017).

Although the Riroriro pilot shows promise, the results of this study should be interpreted with caution. As a pilot, the present analysis was limited by the small number of participants in the programme, resulting in limited capabilities to generalise these results to other applications of the programme in the same, or different school environments. The results of this research would be strengthened by further research in which the classroom outcomes are mapped and measured at the beginning (baseline) and end (the follow up) of the school year using well validated measures of emotional regulation/dysregulation.

\section{Conclusion}

Despite the limitations, the results of this study are encouraging and can be used preliminarily by researchers and practitioners as well as support the need for future research. A trauma-informed Riroriro programme is a powerful tool for educators interested in closing the achievement gap for traumatised youth and supporting these children to successfully engage in a mainstream environment. Supporting all school staff to become trauma-informed through professional development and training should be a high priority.

Open Access This article is licensed under a Creative Commons Attribution 4.0 International License, which permits use, sharing, adaptation, distribution and reproduction in any medium or format, as long as you give appropriate credit to the original author(s) and the source, provide a link to the Creative Commons licence, and indicate if changes were made. The images or other third party material in this article are included in the article's Creative Commons licence, unless indicated otherwise in a credit line to the material. If material is not included in the article's Creative Commons licence and your intended use is not permitted by statutory regulation or exceeds the permitted use, you will need to obtain permission 
directly from the copyright holder. To view a copy of this licence, visit http://creativecommons.org/licen ses/by/4.0/.

\section{References}

American Psychological Association: Zero Tolerance Task Force. (2008). Are zero tolerance policies effective in the schools? An evidentiary review and recommendations. The American Psychologist, $63(9), 852$.

Bath, H. (2008). The three pillars of trauma-informed care. Reclaiming Children \& Youth, 17(3), $17-21$.

Bilmes, J., \& Heroman, C. (2005). Helping children rebound: Strategies for infant \& toddler teachers after the 2005 hurricanes. Retrieved from https://www.brighthorizons.com/resources/pdf/talkt ochildren/docs/Katrina_1105.pdf.

Boyd, E., Lanius, R., \& McKinnon, M. (2018). Mindfulness-based treatments for posttraumatic stress disorder: A review of the treatment literature and neurobiological evidence. Journal of Psychiatry \& Neuroscience, 43(1), 7-25. https://doi.org/10.1503/jpn.170021

Braun, V., \& Clarke, V. (2006). Using thematic analysis in psychology. Qualitative Research in Psychology, 3, 77-101. https://doi.org/10.1191/1478088706qp063oa

Capo, K., Khadam-Hir, J., Paz, D., Vierra, V. Q., \& Young, D. (2017). Look for the helpers, listen for the stories activity guide: Supporting prekindergarten and kindergarten students post-Harvey. Retrieved from: http://glasscock.rice.edu/departments/school-literacy-culture/resources.

Cole, F., O’Brien, G., Gadd, G., Ristuccia, J., Wallace, L., \& Gregory, M. (2005). Helping traumatized children learn: Supportive school environments for children traumatized by family violence. Massachusetts Advocates for Children, 2005933604

Craig, E. (2015). Trauma-sensitive school: Learning communities transforming children's lives, K-5. Teachers College.

Day, A., Somers, C., Baroni, A., West, S., Sanders, L., \& Peterson, C. (2015). Evaluation of a trauma informed school intervention with girls in a residential facility school: Student perceptions of school environment. Journal of Aggression, Maltreatment \& Trauma, 24(10), 1086-1105. https:// doi.org/10.1080/10926771.2015.1079279

Delaney-Black, V., Covington, C., Ondersma, S., Nordstrom-Klee, B., Templin, T., Ager, J., Janisse, J., \& Sokol, R. (2002). Violence exposure, trauma, and IQ and/or reading deficits among urban children. Archives of Pediatrics \& Adolescent Medicine, 156(3), 280-285.

Dorado, J., Martinez, M., McArthur, L., \& Leibovitz, T. (2016). Healthy environments and response to trauma in schools (HEARTS): A whole-school, multi-level, prevention and intervention program for creating trauma-informed, safe and supportive schools. School Mental Health, 8, 163176. https://doi.org/10.1007/s12310-016-9177-0

Durlak, J., Weissber, R., \& Pachan, M. (2010). A meta-analysis of after-school programs that seek to promote personal and social skills in children and adolescents. American Journal of Community Psychology, 45, 294-309. https://doi.org/10.1007/s10464-010-9300-6

Franzen, S. (2019). The impact of trauma-informed strategies on self-regulation and sense of belonging in elementary students. Sophia, the St. Catherine University repository. Retrieved from https://sophia.stkate.edu/maed/340.

Herman, J. (2015). Trauma and recovery: The aftermath of violence, from domestic abuse to political terror. Basic Books.

Herrenkohl, T., Hong, S., \& Verbrugge, B. (2019). Trauma-informed programs based in schools: Linking concepts to practices and assessing the evidence. American Journal of Community Psychology, 64(3-4), 373-388. https://doi.org/10.1002/ajcp.12362

Hepp, J., Schmitz, S., Urbild, J., Zauner, K., \& Niedtfeld, I. (2021). Childhood maltreatment is associated with distrust and negatively biased emotion processing. Borderline Personality Disorder and Emotion Dysregulation, 8(1), 14. https://doi.org/10.1186/s40479-020-00143-5

Howley, P., Thomas, S., Sweeney, D., \& Vanderhaar, J. (2019). Moving beyond schedules, testing and other duties as deemed necessary by the principal: The school counselor's role in trauma informed practices. Middle School Journal, 50(4), 26-34. https://doi.org/10.1080/00940771. 2019.1650548 
Humble, J., Summers, L., Villarreal, V., Styck, M., Sullivan, R., Hechler, M., \& Warren, S. (2018). Childcentered play therapy for youths who have experienced trauma: A systematic literature review. Journal of Child \& Adolescent Trauma, 12(3), 365-375. https://doi.org/10.1007/s40653-018-0235-7

Hurt, H., Malmud, E., Brodsky, L., \& Giannetta, J. (2001). Exposure to violence: Psychological and academic correlates in child witnesses. Archives of Pediatrics \& Adolescent Medicine, 155(12), 13511356. https://doi.org/10.1001/archpedi.155.12.1351

Ludy-Dobson, C., \& Perry, B. (2010). The role of healthy relational interactions in buffering the impact of childhood trauma. From: Working with children to heal interpersonal trauma: The power of play. The Guilford Press.

Mancini, M. (2020). A pilot study evaluating a school-based, trauma-focused intervention for immigrant and refugee youth. Child and Adolescent Social Work, 37, 287-300. https://doi.org/10.1007/ s10560-019-00641-8

National Child Traumatic Stress Network Schools Committee. (2008). Child trauma toolkit for educators. National Center for Child Traumatic Stress.

National Child Traumatic Stress Network, Schools Committee. (2017). Creating, supporting, and sustaining trauma-informed schools: A system framework. National Center for Child Traumatic Stress.

Oehlberg, B. (2008). Why schools need to be trauma informed. Trauma and Loss: Research and Interventions, 8(2), 1-4.

Overstreet, S., \& Chafouleas, S. (2016). Trauma-informed schools: Introduction to the special issue. School Mental Health, 8, 1-6. https://doi.org/10.1007/s12310-016-9184-1

Perry, D., Pollard, A., Blakley, L., Baker, L., \& Vigilante, D. (1995). Childhood trauma, the neurobiology of adaptation and use-dependent development of the brain: How states become traits. Infant Mental Health Journal, 76(4), 271-291.

Pihama, L., Smith, L., Evans-Campbell, T., Kohu-Morgan, H., Cameron, N., Mataki, T., Te Nana, R., Skipper, H., \& Southey, K. (2017). Investigating Maori approaches to trauma informed care. Journal of Indigenous Wellbeing, 2(3), 18-31.

Porche, V., Fortuna, R., Lin, J., \& Alegria, M. (2011). Childhood trauma and psychiatric disorders as correlates of school dropout in a national sample of young adults. Child Development, 82(3), 982-998.

Putnam, F. W. (2006). The impact of trauma on child development. Juvenile and Family Court Journal, $57(1), 1-11$.

Rodenbush, K. (2015). The effects of trauma on behavior in the classroom [Presentation materials]. Monterey County, Office of Education website. Retrieved from http://www.montereycoe.org/Assets/ selpa/Files/Presentation-Materials/The $\% 20$ Effects $\% 20$ of $\% 20$ Trauma $\% 20$ on $\% 20$ Behavior $\% 20 \mathrm{in} \%$ 20the\%20Classroom.pdf.

Scarpa, A., \& Reyes, N. (2011). Improving emotion regulation with CBT in young children with high functioning autism spectrum disorders: A pilot study. Psychotherapy, 39, 495-500. https://doi.org/ $10.1017 / \mathrm{S} 1352465811000063$

Shamblin, S., Graham, D., \& Bianco, J. (2016). Creating trauma-informed schools for rural appalachia: The partnerships program for enhancing resiliency, confidence and workforce development in early childhood education. School Mental Health, 8, 189-200. https://doi.org/10.1007/s12310-016-9181-4

Streeck-Fischer, A., \& van der Kolk, B. A. (2000). Down will come baby, cradle and all: Diagnostic and therapeutic implications of chronic trauma on child development. Australian and New Zealand Journal of Psychiatry, 34(6), 903-918.

Substance Abuse and Mental Health Services Administration. (2003). What is child traumatic stress? Retrieved May 4, 2020, from https://www.samhsa.gov/sites/default/files/programs_campaigns/child rens_mental_health/what-is-child-traumatic-stress.pdf.

Tobin, M. (2016). Childhood trauma: Developmental pathways and implications for the classroom. Australian Council for Educational Research (ACER). Retrieved February 10, 2022, from https://resea rch.acer.edu.au/learning_processes/20.

Walsh, M., Joyce, S., Maloney, T., \& Vaithianathan, R. (2019). Adverse childhood experiences and school readiness outcomes; results from the growing up in New Zealand Study. Centre for Social Data Analytics, Auckland University of Technology, 978-1-98-854157-0.

Publisher's Note Springer Nature remains neutral with regard to jurisdictional claims in published maps and institutional affiliations. 